\title{
VLDL Cholesterol Subtype 2 Measurement
}

National Cancer Institute

\section{Source}

National Cancer Institute. VLDL Cholesterol Subtype 2 Measurement. NCI Thesaurus.

Code C120668.

The determination of the very low density lipoprotein cholesterol subtype 2 present in a sample. 